\title{
Kinetic Studies on the Radical Polymerization of Butadiene Derivatives
}

\author{
Mikiharu KAMACHI, Hiroyuki UMETANI, and Shun-ichi NOZAKURA \\ Department of Macromolecular Science, Faculty of Science, \\ Osaka University, Toyonaka, Osaka 560, Japan
}

(Received July 22, 1985)

\begin{abstract}
A kinetic study on the radical polymerization of diene compounds was carried out at $25 \pm 0.001^{\circ} \mathrm{C}$. The diene compounds were ethyl pentadienoate and its derivatives $\mathrm{CH}_{2}=\mathrm{CX}-\mathrm{CH}=\mathrm{CHCOOCH}_{2} \mathrm{CH}_{3}\left(\mathrm{EP}: \mathrm{X}=\mathrm{H}, \mathrm{EMP}: \mathrm{X}=\mathrm{CH}_{3}\right.$, and $\left.\mathrm{EEP}: \mathrm{X}=\mathrm{OCH}_{3}\right)$, and 1acetoxybutadiene $(\mathrm{AB})$. Elementary rate constants of these diene compounds were determined by the rotating sector method; the values of $k_{\mathrm{p}}$ and $k_{\mathrm{t}}$ for EP, EMP, EEP, and AB were 30.9 and $1.9 \times 10^{7}, 29.7$ and $2.3 \times 10^{7}, 9.9$ and $0.93 \times 10^{7}$, and 18.0 and $28.1 \times 10^{7} \mathrm{M}^{-1} \mathrm{~s}^{-1}$, respectively. These $k_{\mathrm{p}}$ values are lower than those reported for styrene, MMA, methyl acrylate, and vinyl acetate. Cross-propagation rate constants $\left(k_{12}\right.$ and $\left.k_{21}\right)$ were estimated from the $k_{\mathrm{p}}$ values and monomer reactivity ratios in the copolymerizations of these dienes $\left(M_{2}\right)$ with styrene $\left(M_{1}\right)$. Reactivity of the monomers and the propagating radicals was compared with vinyl compounds and other dienes by using $k_{12}$ and $k_{21}$, respectively. Lower $k_{\mathrm{p}}$ values of these dienes are primarily ascribed to the fact that the decrease in the reactivity of the propagating radical is larger than the increase in that of monomer. Change in radical reactivity among dienes is larger than that in their monomer reactivity. Effects of the resonance stabilization of the propagating radicals on $k_{t}$ were not clearly evident in these radical polymerizations which are discussed on the basis of the preexponential factor.
\end{abstract}

KEY WORDS Radical Polymerization / Dienes / Ethyl Pentadienoate / Ethyl 4-Ethoxy-2,4-pentadienoate / Ethyl 4-Ethoxy-2,4 Pentadienoate / Propagation Rate Constant / Termination Rate Constant / CrossPropagation Rate Constant / Ionization Potential / Half-Wave Potential /

In the previous work, we prepared alternating copolymers of vinyl ether-ethyl acrylate and ketone-acrylonitrile by hydrogenation of 1,3-disubstituted butadiene polymers. ${ }^{1}$ In the course of the study, we came across the fact that polymerization rates of the dienes are lower than those of conventional vinyl monomers such as vinyl acetate, methyl methacrylate and styrene, although high molecular weight polymers were obtained from the dienes by radical polymerization. ${ }^{1}$

A lot of papers have been published on the radical polymerization of butadiene $e^{2,3}$ and monosubstituted butadienes. ${ }^{4-16}$ However, only a few data are available for the elementary rate constants for dienes. ${ }^{17,18}$ To our knowl- edge, no available data have been reported on the rate constants of radical polymerization of 1,3-disubstituted butadienes. We previously performed an ESR study on the radical polymerization of dienes and found that the propagating radical ends are allylic radicals whose unpaired electron was completely delocalized over the three carbons of the chain ends. $^{18}$

In this paper, we determined the elementary rate constants for some diene compounds, and discuss the reactivity of the polymerizing radicals on the basis of the cross-propagation rate constants in the copolymerizations with styrene. Dienes used are ethyl pentadienoate, its derivatives, and 1-acetoxybutadiene. 
Abbreviation:

$$
\begin{aligned}
& \mathrm{CH}_{2}=\mathrm{CX}-\mathrm{CH}=\mathrm{CHCOOCH}_{2} \mathrm{CH}_{3} \\
& \mathrm{X}=\mathrm{H} \text { EP } \\
& \mathrm{CH}_{3} \text { EMP } \\
& \mathrm{OCH}_{3} \text { EEP } \\
& \mathrm{CH}_{2}=\mathrm{CH}-\mathrm{CH}=\mathrm{CHOCOCH}_{3} \text { AB }
\end{aligned}
$$

\section{EXPERIMENTAL}

Dienes were prepared and purified as previously described. ${ }^{1,18}$ Polymerizations were performed using AIBN as an initiator under irradiation by a high pressure mercury lamp with filters for $365 \mathrm{~nm} .^{22}$ Polymerizations were followed by a dilatometer at $25 \pm$ $0.001^{\circ} \mathrm{C} .1^{19,20}$ In the dilatometry, the meniscus rose at first for a few minutes after the onset of irradiation, and then started to drop. This phenomenon is ascribed to thermal expansion of the polymerization system due to the evolution of the heat of polymerization. Therefore, we started the dilatometry measurements from the time when the meniscus came again to the original position. The lifetime of the propagating radical was determined by the rotating sector method. ${ }^{19-22}$ Initiation rates were estimated from the relation between the concentration of the inhibitors and the lengths of the induction periods. 2,2,6,6-Tetramethylpiperidin-1-oxyl (TEMPOL) was used as an inhibitor for the determination of the initiation rate, because TEMPOL has no absorption at $365 \mathrm{~nm}$ and is a good radical scavenger. ${ }^{23}$ The induction period was estimated from the difference between the times when the meniscus of the dilatometer started to fall down from the original position in the absence and in the presence of TEMPOL. The viscosities of diene compounds were measured at $30^{\circ} \mathrm{C}$ using an Ubbelohde viscometer. ${ }^{24}$

The $\mathrm{He}(\mathrm{I})$ photoelectron spectra were measured with the ionization energy scale calibrated with xenon $(\mathrm{IP}=12.130 \mathrm{eV})$ as an internal standard. The spectral resolution was kept less than $35 \mathrm{meV}$ for the ${ }^{2} P_{3 / 2}$ xenon peak.

Polarography was measured with a Voltammetric Analyser, Yanagimoto Model P1000 using solutions of $2 \mathrm{M}$ dienes with $0.1 \mathrm{M}$ tetraethylammonium perchlorate in acetonitrile. A saturated calomel electrode (SCE) was used as a reference electrode and a platinum wire as a counter electrode. An agar-salt bridge prepared from $0.1 \mathrm{M} \mathrm{Na}_{2} \mathrm{SO}_{4}$ solution was used as a junction between the SCE and sample.

\section{RESULTS AND DISCUSSION}

\section{Ionization Potential and Half-Wave Potential of Diene Compounds}

In order to get information on the reactivity of diene compounds, their ionization potentials and half-wave potentials were measured by photoelectron spectrometry and polarography, respectively. Spectra of the photoelectron spectrometry are shown in Figure 1. The interpretation of these spectra were aided by comparison with the CNDO molecular orbital methods of the monomers. The first ionization of these monomers was assigned to the electron-release from the highest occupied-orbital. The results are shown in Table I which includes data for ethyl acrylate (EA) and vinyl acetate (VAc), 25 and indicate that the first ionization decreased in the order: EA $>$ VAc $>$ EP $>$ EEP $>$ EMP $>$ $A B$. The ionization potential of VAc was about $1.5 \mathrm{eV}$ larger than that of the corresponding diene compound $\mathrm{AB}$ and that of EA $1.0 \mathrm{eV}$ larger than that of EP. Half-wave potentials $\left(-E_{1 / 2}\right)$ are also shown in Table I, and decrease in the order: $\mathrm{AB}>\mathrm{EMP}>\mathrm{EP}>$ EEP. The half-wave potentials of EP and $A B$ were less than those of EA and VAc, respectively. ${ }^{26}$

Smaller ionization potentials and smaller half wave potentials of dienes show that the chemical reactivity of dienes is higher than 

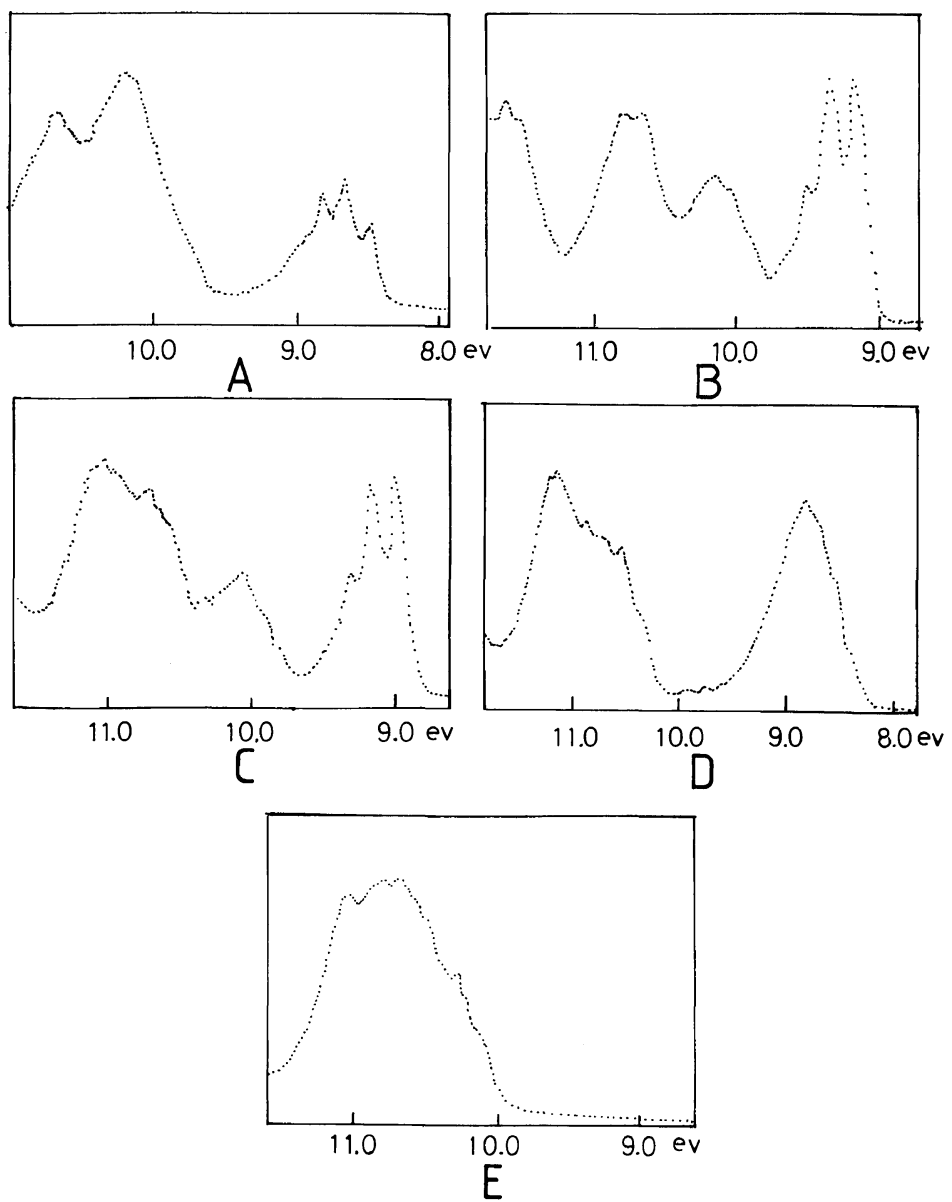

Figure 1. Photoelectron spectra of dienes and ethyl acrylate(EA): A) EEP; B) EP; C) EMP; D) AB; E) EA.

Table I. Ionızation potentials $\left(I_{\mathrm{p}}\right)$ and half wave potentials $\left(-E_{1 / 2}\right)$ of diene and vinyl compounds

\begin{tabular}{lcc}
\hline & \multicolumn{1}{c}{$I_{\mathrm{p}}$} & $\frac{-E_{1 / 2}}{\mathrm{n}}$ \\
\cline { 2 - 3 } & $\mathrm{eV}$ & $\mathrm{V}$ \\
\hline EEP & 8.46 & 1.65 \\
EMP & 8.94 & 1.83 \\
EP & 9.14 & 1.80 \\
$\mathrm{AB}$ & 8.35 & 2.42 \\
EA & 10.14 & $2.95^{\mathrm{b}}$ \\
VAc & $9.85^{\mathrm{a}}$ & $3.50^{\mathrm{b}}$ \\
\hline
\end{tabular}

a From Houk et al. ${ }^{25}$

b From Yamazaki et l. $^{26}$ that of the corresponding vinyl compounds.

\section{Polymerization and Initiation Rates}

The rates of the radical polymerization $\left(R_{\mathrm{p}}\right)$ of dienes were determined in bulk using AIBN as an initiator under steady illumination. These results are shown in Table II, and indicate that $R_{\mathrm{p}}$ 's of dienes are much smaller than those of vinyl monomers and decrease in the order: $\mathrm{EP}>\mathrm{EMP}>\mathrm{EEP}>\mathrm{AB}$.

To estimate the initiation rates $\left(R_{\mathrm{i}}\right)$ of dienes with AIBN, the relation between the concentrations of inhibitors added and induction periods was investigated using TEMPOL 


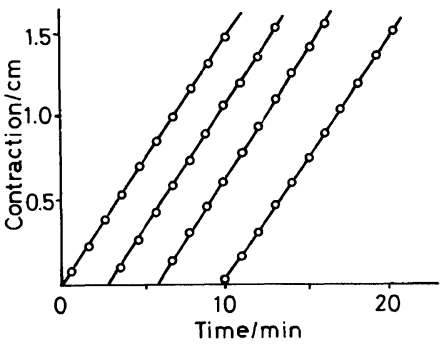

(A)

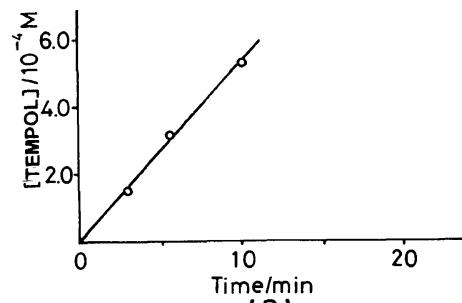

(B)

Figure 2. A) Inhibitory action of TEMPOL in the radicalpolymerization of EMP. [TEMPOL]: (a) $0 \mathrm{mM}$,

(b) $0.17 \mathrm{mM}$, (c) $0.33 \mathrm{mM}$, and (d) $0.55 \mathrm{mM}$.

B) Relation between induction period and concentration of inhibitor.

Table II. Rates and lifetimes for the radical polymerizations of dienes in bulk at $25^{\circ} \mathrm{C}$

\begin{tabular}{|c|c|c|c|c|}
\hline \multirow{2}{*}{ Monomer } & {$[\mathrm{M}]$} & $R_{\mathrm{p}} \times 10^{5}$ & $R_{\mathrm{i}} \times 10^{7}$ & $\tau$ \\
\hline & M & $\mathrm{Ms}^{-1}$ & $\mathrm{Ms}^{-1}$ & $\mathrm{~s}$ \\
\hline EEP & 5.76 & 1.57 & 7.11 & 0.39 \\
\hline EMP & 6.64 & 4.05 & 9.73 & 0.21 \\
\hline EP & 7.38 & 5.94 & 13.04 & 0.20 \\
\hline$A B$ & 8.41 & 0.66 & 5.39 & 0.08 \\
\hline
\end{tabular}

$[\mathrm{AIBN}]=17.5 \mathrm{mM}$.

as an inhibitor. The polymerization in the presence of TEMPOL took place at the same rate after induction period as that in the absence of TEMPOL as shown in Figure 2(A). A linear relation between the concentration of TEMPOL and induction period was observed in polymerization systems of all diene monomers. A typical example is shown in Figure 2(B). Initiation rates were determined from the slope of the line. The results are
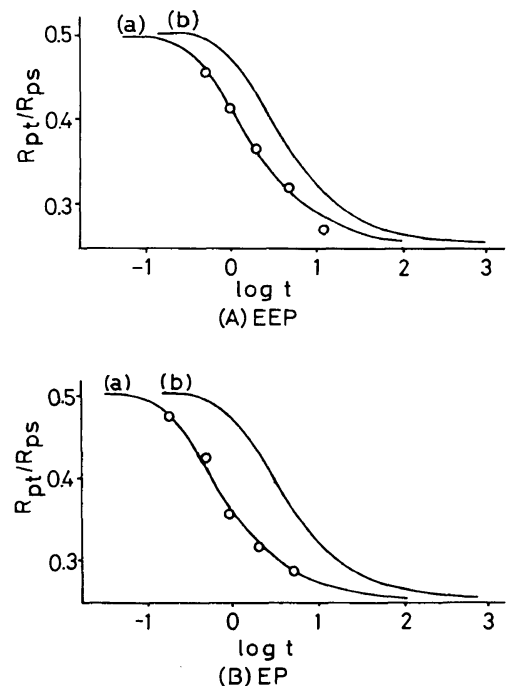

Figure 3. Determination of lifetime of propagating radicals in radical polymerizations of EEP and EP at $25^{\circ}$ C. $[\mathrm{AIBN}]=17.5 \mathrm{mM}$. Ratio of dark to light $=3 . R_{\mathrm{ps}}$, $R_{\mathrm{p}}$ under continuous illumination; $R_{\mathrm{p}}, R_{\mathrm{p}}$ under intermittent illumination. (a) experimental curve; (b), theoretical curve of lifetime of $1 \mathrm{~s}$. (A) EEP; (B) EP.

summarized in Table II, and indicate that $R_{\mathrm{i}}$ decreases in the order: $\mathrm{EP}>\mathrm{EMP}>\mathrm{EEP}>$ AB. This order could not be correlated with the physicochemical properties of monomers such as $Q$ values, ${ }^{18}$ ionization potentials, and half-wave potentials (Table I). Other factors such as the viscosity of the reaction system might participate in the initiator efficiency.

\section{Lifetime and Rate Constants}

The mean lifetime of the propagating radical was determined by the intermittent illumination method (ratio of dark to light $=$ $3: 1$ ) at $25 \pm 0.001{ }^{\circ} \mathrm{C}$. Figure 3 shows typical examples of the change of polymerization rate of $\mathrm{AB}$ and EEP with illumination time. The mean lifetimes of growing chains were determined by sliding the theoretical curve for a lifetime of one second over the plots of the experimental data until a best fit was achieved. The experimental data are in agreement with the theoretical values. The mean deviation of the lifetime was estimated to be less 
Table III. Rate constants for the radical polymerization of dienes and vinyl monomers $\left(25^{\circ} \mathrm{C}\right)$

\begin{tabular}{|c|c|c|c|c|}
\hline & $k_{\mathrm{p}}$ & $k_{\mathrm{t}} \times 10^{-7}$ & $\eta\left(30^{\circ} \mathrm{C}\right)$ & $k_{\mathrm{\imath}} \eta \times 10^{-7}$ \\
\hline & $\mathbf{M}^{-1} \mathrm{~s}^{-1}$ & $M^{-1} s^{-1}$ & poise & $\mathbf{M}^{-1} \mathrm{~s}^{-1}$ poise \\
\hline EEP & 9.9 & 0.93 & 4.39 & 4.1 \\
\hline EMP & 29.7 & 2.3 & 2.41 & 5.5 \\
\hline $\mathrm{EP}$ & 30.9 & 1.9 & 1.61 & 3.0 \\
\hline $\mathrm{AB}$ & 18.0 & 28.1 & 2.18 & 61.8 \\
\hline St & $44.0^{a}$ & $4.75^{\mathrm{a}}$ & $0.69^{\mathrm{e}}$ & 3.1 \\
\hline MMA & $410^{\mathrm{b}}$ & $4.27^{\mathrm{b}}$ & $0.63^{\mathrm{e}}$ & 2.7 \\
\hline MA & $1580^{\mathrm{c}}$ & $5.5^{\mathrm{c}}$ & $1.39^{\mathrm{e}}$ & 7.6 \\
\hline VAc & $1012^{d}$ & $5.88^{d}$ & $0.49^{\mathrm{e}}$ & 2.9 \\
\hline
\end{tabular}

than $30 \%$, considering the deviation of the experimental data at illumination time from $0.1 \mathrm{~s}$ to $1 \mathrm{~s}$ from the theoretical curve. The mean lifetimes of five runs are shown in Table II. The $k_{\mathrm{p}}$ and $k_{\mathrm{t}}$ values were estimated from $k_{\mathrm{p}}{ }^{2} / k_{\mathrm{t}}$ and $k_{\mathrm{p}} / k_{\mathrm{t}}$ obtained from $R_{\mathrm{p}}{ }^{2} / R_{\mathrm{i}}[\mathrm{M}]^{2}$ and $R_{\mathrm{p}} /[\mathrm{M}]$, respectively. The values of $k_{\mathrm{p}}$ and $k_{\mathrm{t}}$ thus obtained are shown in Table III along with the data reported for styrene, ${ }^{27} \mathrm{MMA},{ }^{28}$ MA, ${ }^{29}$ and VAc. ${ }^{30}$ The $k_{\mathrm{p}}$ values for dienes are smaller than those for vinyl monomers, decreasing in the order: $\mathrm{MA}>\mathrm{VAc}>\mathrm{MMA}$ $>\mathrm{St}>\mathrm{EP}>\mathrm{EMP}>\mathrm{AB}>\mathrm{EEP}$. This order of the propagation rate constants could not be correlated with $Q$ values, ${ }^{16}$ ionization potentials, and half-wave potentials of monomers. Since $k_{\mathrm{p}}$ is influenced not only by the reactivity of monomers but also by that of the propagating radicals, the relation between $k_{\mathrm{p}}$ ' and physical properties of monomers might not be simple.

\section{Monomer and Radical Reactivity}

In order to understand separately the reactivity of the propagating radicals and monomers, the cross propagation rate constants $\left(k_{12}\right.$ and $\left.k_{21}\right)$ were estimated from the $k_{\mathrm{p}}$ values and $r_{1}$ or $r_{2}$ values. ${ }^{18}$ The results are shown in Table IV. Monomer reactivity was estimated from $k_{12}$ values which are rate
Table IV. Cross-propagation rate constants of the copolymerization of styrene $\left(\mathrm{M}_{1}\right)$ with diene and vinyl monomers $\left(\mathrm{M}_{2}\right)$

\begin{tabular}{lcr}
\hline & $k_{12}{ }^{a}$ & $\frac{k_{21}{ }^{\mathrm{b}}}{n}$ \\
\cline { 2 - 3 } & $\mathrm{M}^{-1} \mathrm{~s}^{-1}$ & $\mathrm{M}^{-1} \mathrm{~s}^{-1}$ \\
\hline EEP $^{\mathrm{c}}$ & 1550 & 0.9 \\
EMP $^{\mathrm{c}}$ & 2070 & 2.8 \\
EP $^{\mathrm{c}}$ & 1380 & 5.4 \\
$\mathrm{AB}^{\mathrm{c}}$ & 276 & 10.1 \\
MMA $^{\mathrm{d}}$ & 85 & 667 \\
MA $^{\mathrm{e}}$ & 53 & 8780 \\
VAc $^{\mathrm{f}}$ & 0.8 & 101200 \\
\hline
\end{tabular}

a $k_{12}=k_{11} / r_{1}$, where $k_{11}=k_{\mathrm{p}}$ for styrene.

b $k_{21}=k_{22} / r_{2}$, where $k_{22}=k_{\mathrm{p}}$ for other monomers.

c Ref 18.

${ }^{d}$ Ref.31.

e $\operatorname{Ref} 32$.

f Ref.33.

For $r_{1}$ and $r_{2}$ values, respectively.

constants for the addition reaction of each monomers with the polystyryl radical, and radical reactivity from $k_{21}$ values which are rate constants for the addition reaction of each radical to styrene. The $k_{12}$ values decreased in the order: EMP $>$ EEP $>$ EP $>$ $\mathrm{AB}>\mathrm{St}>\mathrm{MMa}>\mathrm{MA}>\mathrm{VAc}$. This order was correlated with the $Q$ values of the monomers: the larger the $Q$ value, the larger $k_{21}$. Therefore, it is concluded that the monomer reactivity is dominated by the resonance stabilization of the resulting radical. On the other hand, the reactivity of the propagating radical decreased as follows: VAc $>$ MA $>$ MMA $>$ $\mathrm{St}>\mathrm{AB}>\mathrm{EP}>\mathrm{EMP}>\mathrm{EEP}$. This order is opposite to that of $k_{12}$ except for the order of EEP and EMP, indicating that the reactivity of the propagating radicals increases with the decrease in their resonance stabilization. The exception of EMP and EEP is possibly attributed to the participation of polar factor in the reactivity. Monomer reactivity changed in the range of $10,{ }^{3}$ while radical reactivity in the range of $10^{5}$ (Table IV). Accordingly, smaller $k_{\mathrm{p}}$ values of dienes as compared with those of vinyl monomers are mainly ascribed to the 
fact that the decrease in the reactivity of the propagating radicals due to the resonance stabilization is larger in magnitude than the corresponding increase in the monomer reactivity toward free radicals.

\section{Termination Reaction}

Since the propagating radicals of dienes are stabilized through delocalization over three carbon atoms of their chain ends, ${ }^{18} k_{\mathrm{t}}$ values of the dienes are considered to be smaller than those of vinyl compounds. The $k_{t}$ values of dienes except for $\mathrm{AB}$ seem to be a little smaller than those of vinyl monomers (Table III). However, the effects of viscosity on $k_{t}$ should be taken into account for comparison of the $k_{\mathrm{t}}$ values among diene and vinyl compounds, because $k_{\mathrm{t}}$ is usually considered inversely proportional to the viscosity of the reaction system. ${ }^{19-21}$ In order to remove the effects of viscosity $(\eta)$ on $k_{\mathrm{t}}, k_{\mathrm{t}} \eta$ values were used for comparison of the termination reaction (Table III). Viscosities of dienes at $30^{\circ} \mathrm{C}$ were used in the calculation of $k_{\imath} \eta$ values in Table III, because available data for vinyl compounds were measured at $30^{\circ} \mathrm{C}$, and, in addition, a remarkable difference in the viscosity between $30^{\circ} \mathrm{C}$ and $25^{\circ} \mathrm{C}$ was not found in EP and EMP. These $k_{\mathrm{t}} \eta$ values for pentadienoates $(Q=5.85-8.94)$ were in the same order as those for MMA $(Q=0.75)$ and MA $(Q=0.42)$, and the value for $\mathrm{AB}$ (3.19) was larger than that for VAc $(Q=0.026)$. Therefore, it is not considered that the resonance stabilization of the propagating radicals of diene compounds is the most important factor for lowering in termination rate constants. Since the termination reaction in the radical polymerization is usually diffusioncontrolled, the difference in the rate constant $\left(k_{\mathrm{t}}\right)$ is considered to result from that in the preexponential factor, which is composed of the collision frequency and steric factor (the fraction of effective collision), rather than the activation energy. The difference in $k_{\mathrm{t}} \eta$ between $\mathrm{AB}$ and VAc can be explained by taking into account the preexponential factor, because $A B$, whose unpaired electron of the propagating radical is delocalized over three carbon center, is considered to have a larger preexponential factor than VAc whose propagating end is localized on the center of the chain end. However, the fact that $k_{\mathrm{t}} \eta$ values of pentadienoates are in the same order as those of MMA and MA cannot be explained by this concept. Recently, an ESR study showed that propagating radicals of pentadienoates are more stable through the delocalization over the carbonyl group than that of $\mathrm{AB}{ }^{18} \mathrm{An}$ increase in preexponential factors of pentadienoates as compared with those of MMA and MA might be compensated by a decrease in the reactivity of propagating radicals of pentadienoates due to the resonance stabilization.

In conclusion, the diene compounds generally have higher reactivity than vinyl compounds. But, $k_{\mathrm{p}}$ values for the dienes are smaller than those for vinyl monomers such as VAc, MA, MMA and styrene. The smaller $k_{\mathrm{p}}$ values are mainly ascribed to the fact that a decrease in the reactivity of the propagating radical due to delocalization is larger than an increase in the monomer reactivity toward free radicals. No effects of the stability of the propagating radicals of diene compounds on $k_{\mathrm{t}}$ could be found.

Acknowledgements. The authors thank Prof. S. Ikeda and Dr. I. Watanabe, Department of Chemistry, Faculty of Science, Osaka University, for measurements of photoelectron spectroscopy and Prof. S. Ikeda and Dr. H. Yokoi, Department of Chemistry, Faculty of Science, Osaka University, for polarography measurements.

\section{REFERENCES}

1. M. Kamachi, R. Miwa, and S. Nozakura, Polym. J., 12, 899 (1980).

2. W. H. Bailey, "Vinyl and Dienw Monomers," Part 
II, E. C. Loonard, Ed., Wiley-Interscience, New York; N. Y., 1971, pp 912-917 and 1106-1107.

3. W. H. Saltman, "Encyclopedia of Polymer Science and Technology," Vol. 2, H. Mark, N. G. Gaylord, and N. M. Bikales, Ed., Interscience, New York, N.Y., 1965, pp 678-754.

4. T. Fueno, T. Tsuruta, K. Akimoto, and J. Furukawa, J. Polym. Sci., A-1, 9, 163 (1971).

5. M. Ohtsuki, T. Masuda, and T. Higashimura, $J$. Polym. Sci., Polym. Chem. Ed., 14, 1157 (1976).

6. S. Yamashita, S. Atomori, S. Kohjiya, and T. Miyagawa, J. Appl. Polym. Sci., 17, 3049 (1973).

7. S. Yamashita, K. Sando, and S. Kohjiya, J. Appl. Polym. Sci., 23, 1951 (1979).

8. D. H. Lewis, R. C. Kneisel, and B. W. Ponder, Macromolecules, 6, 660 (1973).

9. T. Masuda, M. Ohtsuki, and T. Higashimura, $J$. Polym. Sci., Polym. Chem. Ed., 12, 2065 (1974).

10. H. Ishida and I. Yamafuji, Kobunshi Ronbunshu, 32, 357 (1975).

11. R. Asami, K. Hasegawa, and T. Onoe, Polym. J., 8, 43 (1976).

12. J. C. Greissier, C. C. Pinazzi, and G. Levesque, Makromol. Chem., 176, 341 (1975).

13. Y. Bando and Y. Minoura, J. Polym. Sci., Polym. Chem. Ed., 14, 693 (1976).

14. S. Kohjiya, S. Fujiwara, K. Fujii, and S. Yamashita, Makromol. Chem., 183, 163 (1982).

15. S. Kohjiya, K. Iwata, S. Yamashita, T. Miyamoto, and H. Inagaki, Polym. J., 15, 869 (1983).

16. S. Kohjiya, M. Kurokawa, K. Iwata, Y. Imoto, T. Enoki, and S. Yamashita, Polym. J., 17, 661 (1985).

17. R. Korus and F. O'Driscoll, "Polymer Handbook," 2nd ed, J. Brandrup and F. I. Immergut, Ed., JohnWiley, New York, N. Y., 1975.

18. M. Kamachi, H. Umetani, Y, Kuwae, and S.
Nozakura, Polym. J., 15, 753 (1983).

19. M. Kamachi, J. Satoh, and S. Nozakura, J. Polym. Sci., Polym. Chem. Ed., 16, 1789 (1978).

20. M. Kamachi, D. J. Liaw, and S. Nozakura, Polym. J., 11, 921 (1979).

21. C. H. Bamford and S. Brumby, Makromol. Chem., 105, 222 (1967).

22. M. Kamachi, D. J. Liaw, and S. Nozakura, Polym. J., 9, 307 (1977).

23. M. Kamachi, M. Fujii, S. Ninomiya, S. Katsuki, and S. Nozakura, J. Polym. Sci., Polym. Chem. Ed., 20, 1489 (1982).

24. J. F. Swindells, R. Ullman, and H. Mark, "Physical Method of Organic Chemistry," Part 1, A. Weissberger, Ed., Interscience, New York, N. Y., 1959, pp $701-703$.

25. K. N. Houk and L. L. Munchausen, J. Am. Chem. Soc., 98, 937 (1976).

26. N. Yamazaki, I. Tanaka, and S. Nakahama, J. Macromol Sci., A2, 1121 (1968).

27. R. Korus and F. O'Driscoll, "Polymer Handbook,' 2nd ed., J. Brandrup and F. I. Immergut, Ed., Interscience, New York, N. Y., 1975, II-47.

28. G. M. Burnett, G. G. Cameron, and M. M. Zafur, Eur. Polym. J., 6, 823 (1970).

29. M. S. Matheson, E. E. Auer, E. B. Bevilaequa, and E. J. Hart, J. Am. Chem. Soc., 71, 497 (1949).

30. M. S. Matheson, E. E. Auer, E. B. Bevington, and E. J. Hart, J. Am. Chem. Soc., 73, 1700 (1951).

31. W. J. Burlent and D. H. Green, J. Polym. Sci., 31, 227 (1958).

32. L. S. Lushin and R. J. Myers, "Encyclopedia of Polymer Science and Technology," Vol. 1, Interscience, New York, N. Y., 1964, p 246.

33. F. R. Mayo, C. Walley, F. M. Lewis, and W. F. Hulse, J. Am. Chem. Soc., 70, 1523 (1948). 